\title{
The PI3K/Akt pathway: a critical player in intervertebral disc degeneration
}

\author{
Zhi-Hua Ouyang ${ }^{1,2}$, Wen-Jun Wang ${ }^{2}$, Yi-Guo Yan², Bing Wang1 and Guo-Hua Lv ${ }^{1}$ \\ ${ }^{1}$ Department of Spine Surgery, The 2nd Xiangya Hospital of Central South University, Changsha, China \\ ${ }^{2}$ Department of Spine Surgery, The First Affiliated Hospital, University of South China, Hengyang, China \\ Correspondence to: Guo-Hua Lv, email: Ivguohua66@163.com
}

Keywords: IDD, PI3K, AKt, PTEN, mTOR

Received: November 07, $2016 \quad$ Accepted: May 10,2017 Published: June 27, 2017

Copyright: Ouyang et al. This is an open-access article distributed under the terms of the Creative Commons Attribution License 3.0 (CC BY 3.0), which permits unrestricted use, distribution, and reproduction in any medium, provided the original author and source are credited.

\section{ABSTRACT}

Intervertebral disc degeneration (IDD) is thought to be the primary cause of low back pain, a severe public health problem worldwide. Current therapy for IDD aims to alleviate the symptoms and does not target the underlying pathological alternations within the disc. Activation of the phosphatidylinositol 3-kinase (PI3K)/Akt pathway protects against IDD, which is attributed to increase of ECM content, prevention of cell apoptosis, facilitation of cell proliferation, induction or prevention of cell autophagy, alleviation of oxidative damage, and adaptation of hypoxic microenvironment. In the current review, we summarize recent progression on activation and negative regulation of the PI3K/Akt signaling pathway, and highlight its impact on IDD. Targeting this pathway could become an attractive therapeutic strategy for IDD in the near future.

\section{INTRODUCTION}

Low back pain (LBP) is a major public health problem worldwide, resulting in a huge socioeconomic burden [1-4]. Although the etiology of LBP is complex, intervertebral disc degeneration (IDD) has been regarded as the primary cause [5]. It is acknowledged that genetic predisposition, aging and lifestyles including occupational exposure, smoking, and alcohol consumption are implicated in disc degeneration [6-9]. Although its pathogenesis is not fully elucidated, loss of active IVD cells, progressive breakdown of extracellular matrix (ECM), alternation of intervertebral disc (IVD) cell phenotypes, and excessive inflammatory response have been proposed as critical contributors to IDD [10, 11]. Current therapy for IDD aims to relieve pain and control symptom rather than interfere with its pathophysiology [12]. Although several biological strategies capable of slowing mild and moderate disc degeneration through induction of ECM remodeling have been considered [13-17], their clinical efficacy remains to be determined. Therefore, a better understanding of its pathogenesis is essential to develop effective treatments.
The intervertebral disc (IVD) is made up of the central nucleus pulposus (NP), the peripheral annulus fibrosus (AF) enclosing NP, and the upper and lower cartilaginous endplates (CEPs) [18]. These three distinct anatomic regions form a complicated structure for maintaining spinal stability. The IVD is the biggest avascular tissue in human body, with limited blood supply via peripheral capillaries [19]. Given the fact that the IVD resides in a nutrient deficient environment, disc degeneration is prone to occur if nutrition is depleted or impeded.

Dysregulation of multiple signaling pathways has been shown to be implicated in disc degeneration [20]. As a main intracellular signaling pathways, activation of the phosphatidylinositol 3-kinase (PI3K)/Akt pathway can modulate cell proliferation, apoptosis, autophagy and differentiation under the physiological and pathological conditions by interacting with multiple downstream target proteins, including mammalian target of rapamycin (mTOR) and forkhead box O1 (FoxO1) [21-23]. More importantly, targeting this pathway has shown promise for the prevention or reversal of IDD. In this review, after introduction of the PI3K/Akt pathway, we explore its role in disc degeneration. 


\section{THE PI3K/AKT SIGNALING PATHWAY AND NEGATIVE REGULATORS}

\section{Activation of the PI3K/Akt signaling pathway and downstream effectors}

As a unique family of intracellular lipid kinases, PI3Ks contain three classes (Class I, II and III). Among these, Class I is the most studied, which is subdivided into class IA (PI3K $\alpha, \beta$ and $\delta$ ) and class IB (PI3K $\gamma$ ). Class I PI3Ks are heterodimer that are made up of a catalytic subunit (p110 $\alpha$, $\beta, \gamma$ or $\delta$,) and a regulatory subunit (p85a, $\beta$ or $\gamma$ ) [24]. Akt, a serine/threonine kinase, includes three isoforms (Akt1, 2, and 3). These isoforms have high homology [25].

Class IA and class IB PI3Ks are activated by different agents. Receptor tyrosine kinases (RTKs) are transmembrane glycoproteins with enzymatic activity. PI $3 \mathrm{~K} \alpha, \mathrm{PI} 3 \mathrm{~K} \beta$ and $\mathrm{PI} 3 \mathrm{~K} \delta$ are activated when an extracellular ligand binds to a RTK [26]. In contrast, both G-protein-coupled receptors (GPCRs) and small GTPase Ras are responsible for $\mathrm{PI} 3 \mathrm{~K} \gamma$ activation [22]. Once activated, PI3Ks convert membranebound phosphatidylinositol 4,5-biphosphate (PIP2) into phosphatidylinositol 3,4,5-triphosphate (PIP3) [27]. PIP3 then recruits phosphoinositide- dependent kinase 1 (PDK1) to phosphorylate Akt at threonine 308 (Thr308). Subsequently, mTOR complex 2 (mTORC2) phosphorylates Akt at serine 473 (Ser473) for full AKT activation $[28,29]$. Thereafter, activated Akt interacts with downstream target proteins to regulate multiple biological processes, including apoptosis, autophagy and cell cycle progression (Figure 1).

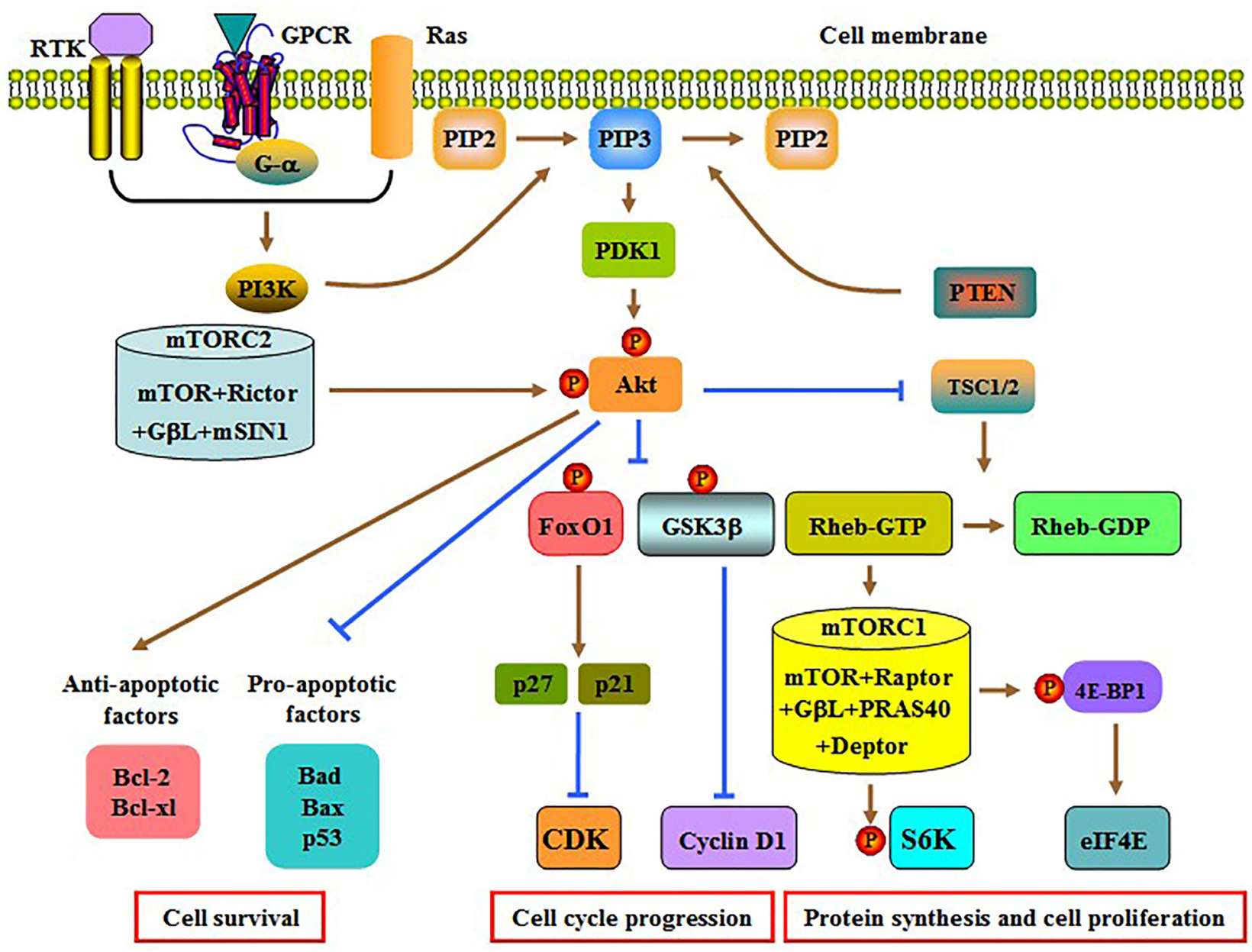

Figure 1: Schematic diagram of the PI3K/AKT pathway. PI3K is activated upon binding of an extracellular ligand to RTK, GPCR or Ras. Activated PI3K converts PIP2 to PIP3, which is able to be reversed by PTEN. PIP3 then recruits PDK1, which phosphorylates and partially activates Akt. The mTORC2 mediates the second phosphorylation to fully activate AKT. Subsequently, the formation of the TSC1/2 heterodimer is significantly decreased, which leads to a marked increase in Rheb-GTP content and mTORC1 activation. The mTORC1 induces S6K phosphorylation to release 4E-BP1, which stimulate protein synthesis and cell proliferation. Akt activation enhances cyclin D1 and CDK expression by inhibiting GSK3 $\beta$ and FoxO1, respectively. Both effects contribute to cell cycle progression. Activated Akt can also suppress apoptosis via regulating the expression of apoptosis-associated genes. Raptor, regulatory-associated protein of mTOR; GßL, mammalian LST8/G-protein $\beta$-subunit like protein; PRAS40, proline-rich Akt substrate 40; Deptor, DEP domain containing mTORinteracting protein; mSIN1, mammalian stress-activated protein kinase interacting protein 1. 
As an evolutionarily conserved serine/threonine protein kinase from yeast to mankind, mTOR interacts with other proteins to form two multiprotein complexes: mTORC1 and mTORC2 [30]. The mTORC1 is extremely sensitive to rapamycin, whereas mTORC2 is insensitive to rapamycin. The activated Akt reduces the formation of tuberous sclerosis complex (TSC) $1 / 2$ and then inhibits the conversion of GTP-Rheb to GDP-Rheb. Increased GTPRheb activates mTORC1 [31]. Subsequently, mTORC1 induces the phosphorylation of ribosomal protein S6 kinase (S6K) and eukaryotic translation initiation factor 4E-binding protein 1 (4E-BP1). Once phosphorylated, the latter stimulates the release of eukaryotic translation initiation factor 4E (eIF4E). Both S6K and eIF4E finally promote protein translation and cell proliferation [32, 33].

Besides mTORC1, Akt is capable of deactivating both glycogen synthase kinase $3 \beta$ (GSK $3 \beta$ ) and FoxO1 by stimulating their phosphorylation $[34,35]$. Inactivation of GSK $3 \beta$ increases the biogenesis of cyclin D1 and then accelerates cell cycle. FoxO1 contains a conserved forkhead domain and three putative phosphorylation sites for Akt. Decreased activity of FoxO1 restrains the transcription of p27 and p21, two inhibitors of cyclin-dependent kinase (CDK), resulting in cell cycle progression [36]. Activated PI3K/Akt signaling can also facilitate cell survival via attenuating pro-apoptotic Bad, Bax and p53 levels as well as enhancing anti-apoptotic Bcl-2 and Bcl-xl levels [37, 38].

\section{Negative regulators}

The major negative regulator of this pathway is phosphatase and tensin homolog (PTEN) that converts PIP3 back to PIP2, an opposite action with PI3K (Figure 1) $[39,40]$. Notably, the activated PI3K/Akt pathway can also facilitate ubiquitin-mediated proteasomal cleavage of PTEN by upregulating the expression of NEDD4-1 (an E3 ligase), leading to permanent activation of this pathway in a positive feedback loop [41, 42]. In addition to PTEN, there are some specific inhibitors targeting PI3K or Akt. The PI3K inhibitors primarily contain LY294002, BYL719 and BKM120. The Akt inhibitors consist of MK2206, GSK690693 and RX0201 [43].

\section{ROLES OF THE PI3K/AKT PATHWAY IN THE PATHOGENESIS OF IDD}

IDD is a complicated disease involving numerous pathologic processes [44]. As expected, the PI3K/Akt pathway takes part in disc degeneration through multiple mechanisms (Figure 2), which will be discussed in detail below.

\section{Increase of ECM content}

The hallmark of IDD is progressive loss of ECM components due to increased production of matrix metalloproteinases (MMPs) and a disintegrin and metalloprotease with thrombospondin motifs (ADAMTSs) [45, 46]. Insulin-like growth factor-1 (IGF-1) has a significant protective effect against IDD [47-49]. Serum (IGF-1) levels were lower in lumbar disc degeneration patients than those of healthy controls, and addition of IGF-1 to human NP SV40 cells induced Akt phosphorylation and then inactivated FoxO1, leading to inhibition of MMP-3 transcription [50]. In rat endplate chondrocytes, addition of IGF-1 dramatically decreased the expression and activity of MMP-13 by activating the $\mathrm{PI} 3 \mathrm{~K} /$ Akt pathway, which increased type II collagen (Col II) content [51]. Additionally, treatment of bovine NP cells with IGF-1 combined bone morphogenetic protein 7 (BMP-7) synergistically promoted aggrecan accumulation by enhancing Akt activity [52]. Accumulating evidence suggests that dysregulation of microRNAs (miRNAs) participates in disc degeneration [53, 54]. Recently, Liu and colleagues observed that miR-4458 levels were significantly increased in degenerative human lumbar disc specimens [55]. They also found that transfection of human NP cells with miR-4458 mimic inhibited the PI3K/ Akt signaling via silencing of insulin-like growth factor 1 receptor (IGF-1R), leading to increased ECM breakdown [55]. Collectively, activated PI3K/Akt pathway contributes to prevention of disc ECM degradation.

In addition to blockade of ECM catabolism, activation of this pathway promotes its anabolism. Sox 9 is an important transcriptional factor that can drive aggrecan gene expression [56-58]. It has been reported that miR-30a attenuates aggrecan content by targeting Sox 9 in primary chondrocytes from cartilage isolated from osteoarthritis donors [59]. In contrast, overexpression of Sox9 dramatically facilitated aggrecan production in cultured human articular chondrocytes [60]. Similarly, activation of the PI3K/AKT signaling increased Sox9 expression and activity, which subsequently induced transcription of aggrecan gene in rat NP cells [61].

\section{Inhibition of cell apoptosis}

In general, apoptosis occurs via two wellcharacterized pathways in mammalian cells: the death receptor or extrinsic pathway and mitochondria or intrinsic pathway [62]. IVD cell loss resulting from excessive apoptosis has long been considered to be an important cause of reduced ECM synthesis during disc degeneration [63-65]. In addition to modulation of intradiscal ECM metabolism, this pathway can suppress apoptosis of IVD cells. Administration of $17 \beta$-estradiol combined with resveratrol (a natural polyphenol compound) promoted Akt phosphorylation and decreased caspase-3 activity, leading to apoptosis inhibition in rat NP cells treated with interleukin-1 $\beta$ (IL-1 $\beta$ ) [66]. Transforming growth factor- $\beta 1$ (TGF- $\beta 1$ ) is a key factor during the development of both cartilage and spine tissues $[67,68]$. Mesenchymal 
stem cell transplantation with pure fibrinous gelatinTGF- $\beta 1$ markedly decreased degenerative degree in a rabbit IDD model [69]. Treatment of rat AF cells with TGF- $\beta 1$ was found to reduce apoptosis incidence by activating the $\mathrm{PI} 3 \mathrm{~K} / \mathrm{AKT} / \mathrm{mTOR}$ pathway under serum deprivation [70]. Conversely, miR-27a overexpression induced apoptosis of human degenerated NP cells via silencing of PI3K [71]. Thus, in vivo delivery of miR-27a inhibitors might be a promising therapeutic strategy to restore the number of viable NP cells for IDD patients.

Sirtuin 1 (SIRT1) is a NAD+-dependent class III histone deacetylase [72]. The protective effects of SIRT1 against disc degeneration are primarily derived from its abilities to promote ECM anabolism, inhibit inflammatory response and alleviate senescence of CEP cells [73-76]. It has been demonstrated that SIRT1 markedly decreases the rate of apoptosis in multiple cell types, such as osteoblast-like MC3T3-E1 cells [77], human kidney proximal tubule epithelial cells [78], cardiomyocytes [79], and chondrocytes [80]. In human degenerative NP cells, SIRT1 was also reported to protect against apoptosis via autophagic induction [81, 82]. Notably, resveratrolinduced SIRT1 activation stimulated Akt phosphorylation and reduced apoptotic incidence of human NP cells, whereas either Akt knockdown or LY294002 abrogated the inhibitory effect of SIRT1 on NP cell apoptosis [83]. In a later study, miR-138-5p knockdown upregulated the expression of its target gene SIRT1 and then inhibited apoptosis in human NP cells treated by tumor necrosis factor- $\alpha$ (TNF- $\alpha)$ [84]. Mechanistically, upregulation of SIRT1 decreased PTEN levels to activate the PI3K/ Akt pathway [84]. These findings reveal the PI3K/AKT signaling as another important mechanism for SIRT1mediated inhibition of NP cell apoptosis. Targeting this pathway might have enormous potential for retarding or reversing disc degeneration.

\section{Promotion of cell proliferation}

Appropriate proliferation of IVD cells represents a tissue repair process during disc degeneration [85]. In addition to blockade of IVD cell apoptosis, this pathway can raise the number of viable IVD cells by promoting cell

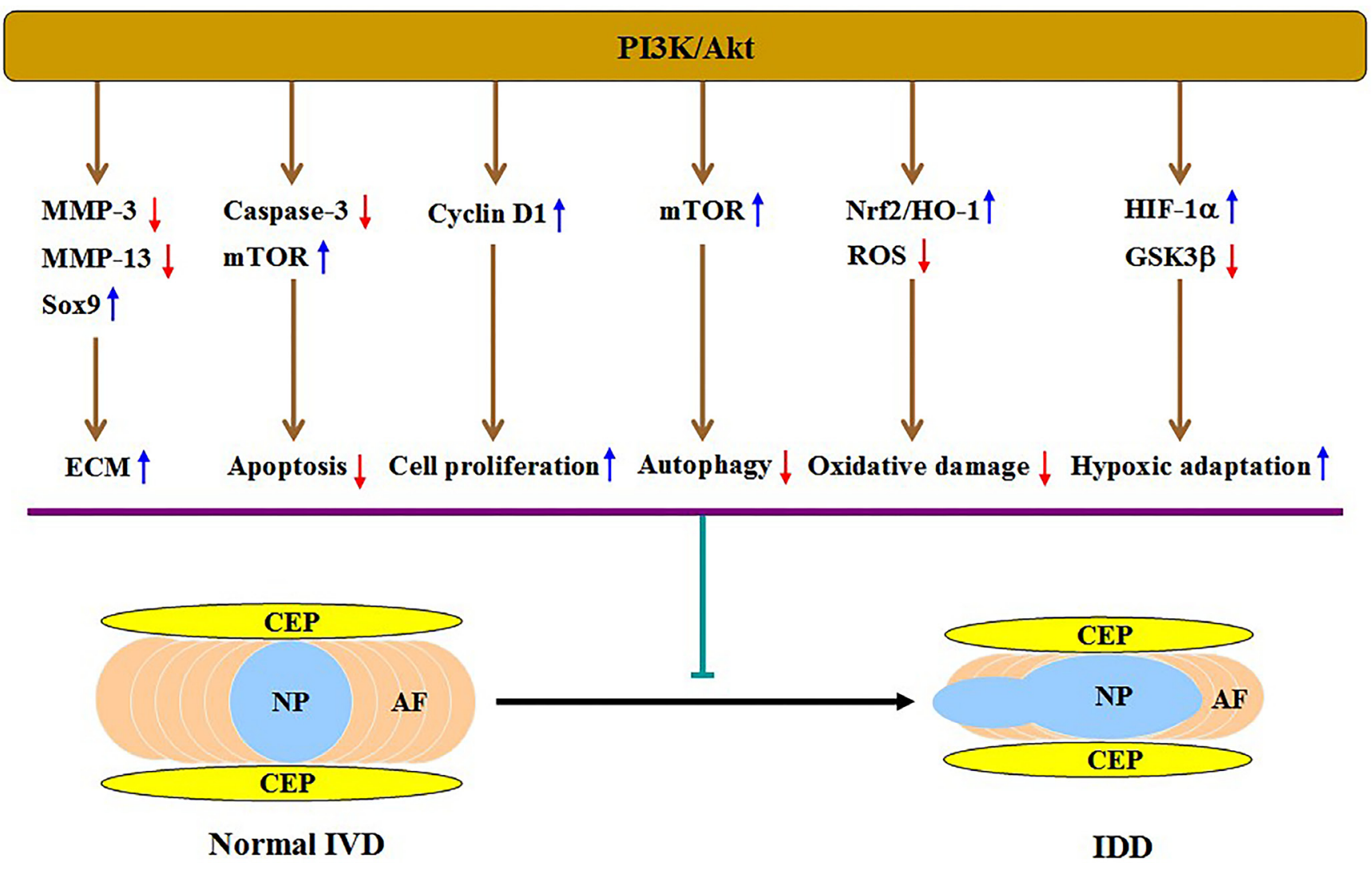

Figure 2: Illustration of PI3K/Akt-mediated protection against IDD and the underlying mechanisms. Activation of this pathway increases ECM content via downregulating MMP-3 and MMP-13 expression and upregulating Sox9 expression, inhibits apoptosis by activating $\mathrm{mTOR}$ and attenuating caspase- 3 activity, and promotes cell proliferation by upregulating cyclin D1 expression. This pathway can also suppress autophagy by activating mTOR, alleviate oxidative injury via activating the Nrf2/HO-1 signaling and decreasing ROS levels, and enhance adaptation of hypoxic microenvironment by upregulating HIF-1 $\alpha$ expression and inactivating GSK3 $\beta$. All of these effects result in alleviation of disc degeneration. 
proliferation. In human IVD cells, exogenous treatment with either PDGF or IGF-1 stimulated DNA synthesis, which was at least partially attributed to activation of this pathway [86]. A similar effect was also observed in bovine coccygeal NP and AF cells [87]. Conversely, high osmolality significantly reduced Akt phosphorylation and then inhibited PDGF or IGF-I-induced synthesis of novel DNA in bovine NP cells [88]. Leptin belongs to a peptide hormone, and its plasma levels are significantly increased in obesity patients. It can be produced by fibrocartilaginous tissues, such as articular cartilage and IVD, besides adipose tissues [89]. Recently, Zhao et al. reported that human herniated disc tissues expressed leptin and its functional receptor, and administration of leptin could stimulate rat NP cell proliferation [90]. Leptin also promoted the proliferation of primary cultured human NP cells [91]. Mechanistically, leptin increased cyclin D1 expression via inhibition of Akt phosphorylation [91]. Thus, the PI3K/AKT signaling may function as a crosstalk between obesity and IDD.

MiR-21 functions as an inducer of cell proliferation [92-94]. Interestingly, transfection of human NP cells with miR-21 mimic dramatically increased Akt activity via targeting PTEN, leading to upregulation of cyclin D1 expression and subsequent cell proliferation [95]. It is worth noting that overexpression of miR-21 could also stimulate these cell proliferation via silencing of programmed cell death 4 (PDCD4) [96]. Recently, Li et al. identified growth arrest specific gene 1 (GAS1) as a direct and functional target of miR-184 [97]. Moreover, ectopic expression of miR-184 markedly attenuated GAS1 levels, which promoted Akt phosphorylation and human NP cell proliferation [97]. Like miR-21 and miR-184, miR-10b is also a multi-functional miRNA. Aberrant expression of this miRNA contributed to the proliferation of malignant tumor cells [98-100]. Similar to these reports, transfection of human NP cells downregulated homeobox D10 (HOXD10) expression, leading to increased Akt phosphorylation and cell proliferation [101]. However, restored expression of HOXD10 or Akt suppression reversed the mitogenic effect of miR-10b [101]. Taken together, miR-21, miR-184 and miR-10b promote NP cell proliferation by activating the $\mathrm{PI} 3 \mathrm{~K} / \mathrm{AKT}$ signaling.

\section{Regulation of cell autophagy}

Autophagy is an orchestrated homeostatic process involving the degradation and digestion of intracellular components by lysosomes [102, 103]. Recent studies have focused on the relationship between autophagy and IDD [104]. There is a low basal level of autophagy in normal NP and AF cells [105]. In contrast, degenerative NP and AF cells exhibited a significant increase in the autophagic activity $[106,107]$. When compared with healthy controls, human degenerated AF tissues showed more autophagic vacuolization and autophagosomes [108]. In NP cells isolated from rat lumbar discs, hydrogen peroxide $\left(\mathrm{H}_{2} \mathrm{O}_{2}\right)$ induced an early autophagic response via the extracellular signal-regulated kinase (ERK)/mTOR pathway; however, prevention of autophagy by 3-methyladenine (3-MA) markedly attenuated the apoptosis of $\mathrm{H}_{2} \mathrm{O}_{2}$-treated NP cells [109]. On the other hand, human degenerative NP cells exhibited a marked decrease in autophagy activity [81]. Importantly, activation of autophagy by rapamycin suppressed IL-1 $\beta$-induced ECM degradation in rat NP cells [110]. Thus, autophagy acts as a double-edged sword in the development of IDD, depending on the stimuli.

The PI3K/Akt pathway is closely associated with autophagy [111, 112]. Recently, $\mathrm{Ni}$ et reported that treatment of rat AF cells with TGF- $\beta 1$ markedly decreased autophagy incidence by activating the PI3K/AKT/mTOR signaling pathway under serum deprivation, leading to increased viable cell number [70]. Notably, IGF1 promoted the survival of human NP cells exposed to compression via autophagy induction, which was abrogated by the specific Akt inhibitor LY294002 [113]. These findings reveal a complex role of this pathway in regulating IVD cell autophagy. This discrepancy may be attributed to the differences in stimuli, cell types and downstream effectors. However, both alterations of autophagy activity contribute to its protection against IDD (Figure 3 ).

\section{Alleviation of oxidative damage}

Oxidative stress is a critical contributor to disc degeneration, because it not only reinforces ECM degradation and inflammatory response, but also reduces the viability and number of IVD cells [114, 115]. Once activated, the PI3K/Akt pathway can enhance endogenous antioxidant ability in multiple cell types, such as macrophages [116], human umbilical vascular endothelial cells [117], and intestinal epithelial cells [117]. Epigallocatechin 3-gallate (EGCG) is known to delay painful disc degeneration by reducing inflammation and catabolism [118]. Recently, Krupkova et al. reported that EGCG administration protected human degenerative NP cells from oxidative stress by promoting Akt phosphorylation [118]. This reveals a novel mechanism by which EGCG protects against IDD. It has been believed that activation of nuclear factor erythroid 2-related factor 2 (Nrf2)/heme oxygenase-1 (HO-1) signaling pathway stimulates the synthesis of antioxidant enzymes such as superoxide dismutase (SOD), catalase (CAT) and glutathione-peroxidase (GSH-Px), leading to enhancement of antioxidant defense system [119, 120]. Moreover, activated PI3K/Akt signaling can promote nuclear translocation of $\mathrm{Nrf} 2$ and subsequent upregulation of HO-1 expression under oxidative stress [121, 122]. Thus, it is likely that activation of $\mathrm{Nrf} 2 / \mathrm{HO}-1$ pathway by the $\mathrm{PI} 3 \mathrm{~K} /$ Akt signaling is, at least partially, responsible for EGCG-mediated attenuation of oxidative damage during IDD.

Mitochondrion dysfunction is a major cause of excessive reactive oxygen species (ROS) production, 
the hallmark of oxidative stress. ROS has been shown to induce NP and AF cell apoptosis through the mitochondria pathway [109, 123, 124]. Noticeably, the PI3K/Akt signaling pathway can affect ROS-stimulated apoptosis in these cells. For example, administration of chlorogenic acid markedly decreased ROS production and inhibited apoptosis by activating the $\mathrm{PI} 3 \mathrm{~K} / \mathrm{Akt}$ signaling in $\mathrm{H}_{2} \mathrm{O}_{2}$ treated rat NP cells [125]. In human degenerative NP cells exposed to $\mathrm{H} 2 \mathrm{O} 2$, EGCG promoted the phosphorylation of Akt, leading to decreased mitochondrial membrane depolarization and increased cellular survival [118]. Taking these findings into account, activating this signaling cascade may be an important approach for alleviation of intradiscal oxidative damage by blocking the mitochondria apoptotic pathway.

\section{Adaptation of hypoxic microenvironment}

Since the disc is avascular, the main components within the disc, including water, aggrecan and fibrillar collagens, proportionally vary considerably depending on the location across the disc. Moreover, there is always a steep concentration gradient of oxygen across the disc, with pO2 falling to as low as $1 \%$ in the center of the disc. Therefore, the IVD resides in a hypoxic microenvironment, which is essential for maintaining its normal physiological functions, including cellular metabolism and protein synthesis [126, 127].

The IVD cells have developed some important mechanisms to ensure their survival in the hypoxic microenvironment of the disc. Hypoxia-inducible factor-1 $\alpha$ (HIF-1 $\alpha)$, an important transcription factor, is responsible for the induction of genes that facilitates adaptation and survival of cells and tissues under hypoxia condition [128]. Risbud et al. detected HIF-1 $\alpha$ expression in rat, human, and sheep NP cells in the presence of either hypoxia or normoxia, and found that these cells consistently expressed functionally active HIF-1 $\alpha$ in the presence of hypoxia [129]. Given the fact that activation of the PI3K/Akt signaling can upregulate HIF-1 $\alpha$ expression under hypoxia in multiple cell types $[130,131]$, this pathway may be also implicated in upregulation of HIF-1 $\alpha$ expression induced by hypoxia in NP cells. On the other hand, Risbud et al. observed that under serum starvation condition, hypoxic contributed to attenuating apoptosis of rat NP cells [132]. Moreover, cell survival in response to hypoxia was associated with activation of the PI3K/Akt/ GSK3 $\beta$ signaling pathway [133]. Thus, activated PI3K/ Akt pathway can enhance the adaptation of NP cells to hypoxic microenvironment.

\section{CONCLUSIONS AND FUTURE PERSPECTIVES}

Although activated PI3K/Akt pathway has been shown to protect against disc degeneration through multiple mechanisms, there are a number of outstanding issues that need to be addressed. One of the most important aspects is the fact that no signaling pathway operates in isolation, which necessitates further

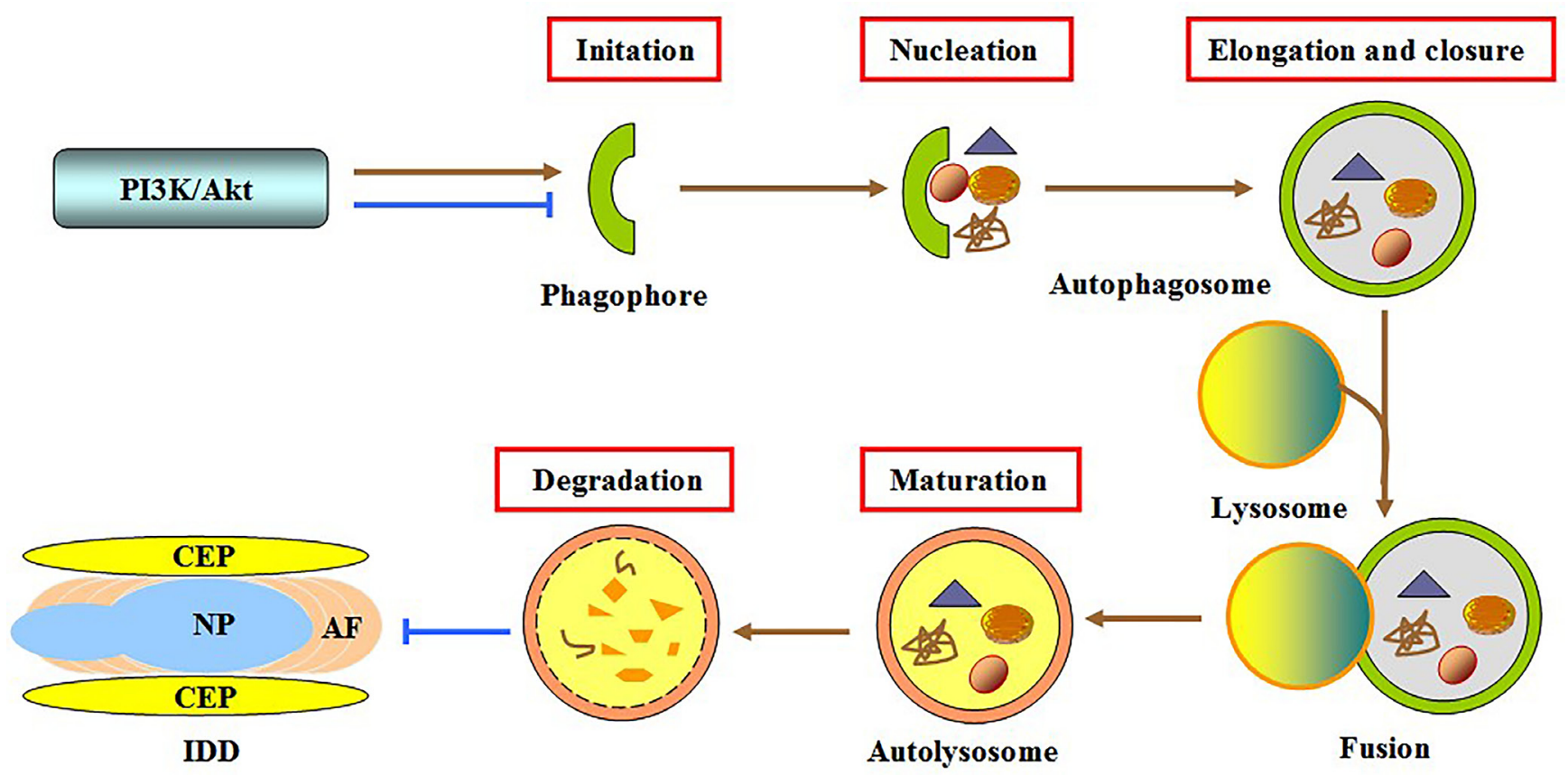

Figure 3: Involvement of autophagy in PI3K/Akt-mediated protection against IDD. Autophagy is a successive process involving the formation of phagophores, autophagosomes and autolysosomes, and degradation of vesicle contents. Activating the PI3K/ AKT pathway can antagonize or induce IVD cell autophagy, thereby leading to inhibition of disc degeneration. 
investigation into how this pathway interacts with other signaling mediators. Establishment and application of chemically defined culture conditions would greatly promote such investigations and diminish non-associated signaling interference. The nuclear factor- $\kappa \mathrm{B}(\mathrm{NF}-\kappa \mathrm{B})$ and mitogen-activated protein kinase (MAPK) signaling pathways have been frequently reported to be implicated in disc degeneration [134-137]. Considering NF- $\kappa B$ and MAPK as downstream effectors of Akt, it is also important to clarify whether this pathway affects the development of IDD via regulation of NF- $\kappa \mathrm{B}$ and MAPK. Hyperactivation of the PI3K/Akt pathway has been frequently reported in a wide variety of malignant tumors $[138,139]$. Whether targeting this pathway in disc degeneration would lead to tumorigenesis is a considerable issue. Like MMPs, ADAMTSs are responsible for the degradation of Col II and aggrecan. It remains unclear whether this pathway inhibits ECM catabolism in the disc through downregulation of ADAMTS expression. In summary, more research into this pathway contribute to developing novel biological treatments for disc degeneration.

\section{ACKNOWLEDGMENTS}

The authors gratefully acknowledge the financial support from the National Natural Sciences Foundation of China (31400802).

\section{CONFLICTS OF INTEREST}

The authors have declared no conflicts of interest.

\section{REFERENCES}

1. Andersson GB. Epidemiological features of chronic lowback pain. Lancet. 1999; 354:581-85.

2. Lin CC, Li Q, Williams CM, Maher CG, Day RO, Hancock MJ, Latimer J, Mclachlan AJ, Jan S. The economic burden of guideline-recommended first line care for acute low back pain. Eur Spine J. 2016 Sep 21. [Epub ahead of print]

3. Dagenais S, Caro J, Haldeman S. A systematic review of low back pain cost of illness studies in the United States and internationally. Spine J. 2008; 8:8-20.

4. Furlan AD, Yazdi F, Tsertsvadze A, Gross A, Van Tulder M, Santaguida L, Cherkin D, Gagnier J, Ammendolia C, Ansari MT, Ostermann T, Dryden T, Doucette S, et al. Complementary and alternative therapies for back pain II. Evid Rep Technol Assess (Full Rep). 2010;194:1-764.

5. Millecamps M, Tajerian M, Naso L, Sage EH, Stone LS. Lumbar intervertebral disc degeneration associated with axial and radiating low back pain in ageing SPARC-null mice. Pain. 2012; 153:1167-79.

6. Battié MC, Videman T, Parent E. Lumbar disc degeneration: epidemiology and genetic influences. Spine. 2004; 29:2679-90.
7. Feng Y, Egan B, Wang J. Genetic Factors in Intervertebral Disc Degeneration. Genes Dis. 2016; 3:178-85.

8. Hemanta D, Jiang XX, Feng ZZ, Chen ZX, Cao YW. Etiology for Degenerative Disc Disease. Chin Med Sci J. 2016; 31:185-91.

9. Vo NV, Hartman RA, Patil PR, Risbud MV, Kletsas D, Iatridis JC, Hoyland JA, Le Maitre CL, Sowa GA, Kang JD. Molecular mechanisms of biological aging in intervertebral discs. J Orthop Res. 2016; 34:1289-306.

10. Weber KT, Jacobsen TD, Maidhof R, Virojanapa J, Overby C, Bloom O, Quraishi S, Levine M, Chahine NO. Developments in intervertebral disc disease research: pathophysiology, mechanobiology, and therapeutics. Curr Rev Musculoskelet Med. 2015; 8:18-31.

11. Kadow T, Sowa G, Vo N, Kang JD. Molecular basis of intervertebral disc degeneration and herniations: what are the important translational questions? Clin Orthop Relat Res. 2015; 473:1903-12.

12. Le Maitre CL, Binch AL, Thorpe AA, Hughes SP. Degeneration of the intervertebral disc with new approaches for treating low back pain. J Neurosurg Sci. 2015; 59:47-61.

13. Noriega DC, Ardura F, Hernández-Ramajo R, MartínFerrero MA, Sánchez-Lite I, Toribio B, Alberca M, García V, Moraleda JM, Sánchez A, García-Sancho J. Intervertebral disc repair by allogeneic mesenchymal bone marrow cells: a randomized controlled trial. Transplantation. 20161; Epub ahead of print

14. Pereira CL, Teixeira GQ, Ribeiro-Machado C, Caldeira J, Costa M, Figueiredo F, Fernandes R, Aguiar P, Grad $\mathrm{S}$, Barbosa MA, Gonçalves RM. Mesenchymal Stem/ Stromal Cells seeded on cartilaginous endplates promote Intervertebral Disc Regeneration through Extracellular Matrix Remodeling. Sci Rep. 2016; 6:33836.

15. Elabd C, Centeno CJ, Schultz JR, Lutz G, Ichim T, Silva FJ. Intra-discal injection of autologous, hypoxic cultured bone marrow-derived mesenchymal stem cells in five patients with chronic lower back pain: a long-term safety and feasibility study. J Transl Med. 2016; 14:253.

16. Vasiliadis ES, Pneumaticos SG, Evangelopoulos DS, Papavassiliou AG. Biologic treatment of mild and moderate intervertebral disc degeneration. Mol Med. 2014; 20:400-09.

17. Priyadarshani P, Li Y, Yao L. Advances in biological therapy for nucleus pulposus regeneration. Osteoarthritis and cartilage / OARS. Osteoarthritis Research Society. 2016; 24:206-12.

18. Le Maitre CL, Pockert A, Buttle DJ, Freemont AJ, Hoyland JA. Matrix synthesis and degradation in human intervertebral disc degeneration. Biochem Soc Trans. 2007; 35:652-55.

19. Boubriak OA, Watson N, Sivan SS, Stubbens N, Urban JP. Factors regulating viable cell density in the intervertebral disc: blood supply in relation to disc height. J Anat. 2013; 222:341-48. 
20. Yang W, Yu XH, Wang C, He WS, Zhang SJ, Yan YG, Zhang J, Xiang YX, Wang WJ. Interleukin-1beta in intervertebral disk degeneration. Clin Chim Acta. 2015; 450:262-72.

21. Li T, Mo H, Chen W, Li L, Xiao Y, Zhang J, Li X, Lu Y. Role of the PI3K-Akt Signaling Pathway in the Pathogenesis of Polycystic Ovary Syndrome. Reprod Sci. 2017; 24:646-55.

22. Zhang J, Yu XH, Yan YG, Wang C, Wang WJ. PI3K/ Akt signaling in osteosarcoma. Clin Chim Acta. 2015; 444:182-92.

23. Jellusova J, Rickert RC. The PI3K pathway in B cell metabolism. Crit Rev Biochem Mol Biol. 2016; 51:359-78.

24. Ahmad A, Biersack B, Li Y, Kong D, Bao B, Schobert R, Padhye SB, Sarkar FH. Targeted regulation of PI3K/Akt/ $\mathrm{mTOR} / \mathrm{NF}-\kappa \mathrm{B}$ signaling by indole compounds and their derivatives: mechanistic details and biological implications for cancer therapy. Anticancer Agents Med Chem. 2013; 13:1002-13.

25. Kumar CC, Madison V. AKT crystal structure and AKTspecific inhibitors. Oncogene. 2005; 24:7493-501.

26. Dobbin ZC, Landen CN. The importance of the PI3K/AKT/ MTOR pathway in the progression of ovarian cancer. Int J Mol Sci. 2013; 14:8213-27.

27. Rubashkin MG, Cassereau L, Bainer R, DuFort CC, Yui Y, Ou G, Paszek MJ, Davidson MW, Chen YY, Weaver VM. Force engages vinculin and promotes tumor progression by enhancing PI3K activation of phosphatidylinositol (3,4,5)-triphosphate. Cancer Res. 2014; 74:4597-611.

28. Majchrzak A, Witkowska M, Smolewski P. Inhibition of the $\mathrm{PI} 3 \mathrm{~K} / \mathrm{Akt} / \mathrm{mTOR}$ signaling pathway in diffuse large B-cell lymphoma: current knowledge and clinical significance. Molecules. 2014; 19:14304-15.

29. Sarbassov DD, Guertin DA, Ali SM, Sabatini DM. Phosphorylation and regulation of Akt/PKB by the rictormTOR complex. Science. 2005; 307:1098-101.

30. Liu P, Gan W, Chin YR, Ogura K, Guo J, Zhang J, Wang B, Blenis J, Cantley LC, Toker A, Su B, Wei W. PtdIns $(3,4,5)$ P3-Dependent Activation of the mTORC2 Kinase Complex. Cancer Discov. 2015; 5:1194-209.

31. Inoki $\mathrm{K}, \mathrm{Li} \mathrm{Y}, \mathrm{Zhu} \mathrm{T}$, Wu J, Guan KL. TSC2 is phosphorylated and inhibited by Akt and suppresses mTOR signalling. Nat Cell Biol. 2002; 4:648-57.

32. Hay N, Sonenberg N. Upstream and downstream of mTOR. Genes Dev. 2004; 18:1926-45.

33. Dowling RJ, Topisirovic I, Alain T, Bidinosti M, Fonseca BD, Petroulakis E, Wang X, Larsson O, Selvaraj A, Liu Y, Kozma SC, Thomas G, Sonenberg N. mTORC1-mediated cell proliferation, but not cell growth, controlled by the 4E-BPs. Science. 2010; 328:1172-76.

34. Zhu Q, Yang J, Han S, Liu J, Holzbeierlein J, Thrasher JB, Li B. Suppression of glycogen synthase kinase 3 activity reduces tumor growth of prostate cancer in vivo. Prostate. 2011; 71:835-45.
35. Jin J, Jin L, Lim SW, Yang CW. Klotho Deficiency Aggravates Tacrolimus-Induced Renal Injury via the Phosphatidylinositol 3-Kinase-Akt-Forkhead Box Protein O Pathway. Am J Nephrol. 2016; 43:357-65.

36. Roy SK, Srivastava RK, Shankar S. Inhibition of PI3K/ AKT and MAPK/ERK pathways causes activation of FOXO transcription factor, leading to cell cycle arrest and apoptosis in pancreatic cancer. J Mol Signal. 2010; 5:10.

37. Zhao GX, Pan H, Ouyang DY, He XH. The critical molecular interconnections in regulating apoptosis and autophagy. Ann Med. 2015; 47:305-15.

38. Duronio V. The life of a cell: apoptosis regulation by the PI3K/PKB pathway. Biochem J. 2008; 415:333-44.

39. Wu H, Goel V, Haluska FG. PTEN signaling pathways in melanoma. Oncogene. 2003; 22:3113-22.

40. Okumura N, Yoshida H, Kitagishi Y, Murakami M, Nishimura Y, Matsuda S. PI3K/AKT/PTEN Signaling as a Molecular Target in Leukemia Angiogenesis. Adv Hematol. 2012;2012:843085.

41. Wang X, Trotman LC, Koppie T, Alimonti A, Chen Z, Gao Z, Wang J, Erdjument-Bromage H, Tempst P, Cordon-Cardo C, Pandolfi PP, Jiang X. NEDD4-1 is a proto-oncogenic ubiquitin ligase for PTEN. Cell. 2007; 128:129-39.

42. Carracedo A, Pandolfi PP. The PTEN-PI3K pathway: of feedbacks and cross-talks. Oncogene. 2008; 27:5527-41.

43. Khan KH, Yap TA, Yan L, Cunningham D. Targeting the PI3K-AKT-mTOR signaling network in cancer. Chin J Cancer. 2013; 32:253-65.

44. Wang SZ, Rui YF, Lu J, Wang C. Cell and molecular biology of intervertebral disc degeneration: current understanding and implications for potential therapeutic strategies. Cell Prolif. 2014; 47:381-90.

45. Wang WJ, Yu XH, Wang C, Yang W, He WS, Zhang SJ, Yan YG, Zhang J. MMPs and ADAMTSs in intervertebral disc degeneration. Clin Chim Acta. 2015; 448:238-46.

46. Vo NV, Hartman RA, Yurube T, Jacobs LJ, Sowa GA, Kang JD. Expression and regulation of metalloproteinases and their inhibitors in intervertebral disc aging and degeneration. Spine J. 2013; 13:331-41.

47. Asfour S, Travascio F, Elmasry S, de Rivero Vaccari JP. A computational analysis on the implications of age-related changes in the expression of cellular signals on the role of IGF-1 in intervertebral disc homeostasis. J Biomech. 2015; 48:332-39.

48. Li B, Zheng XF, Ni BB, Yang YH, Jiang SD, Lu H, Jiang LS. Reduced expression of insulin-like growth factor 1 receptor leads to accelerated intervertebral disc degeneration in mice. Int J Immunopathol Pharmacol. 2013; 26:337-47.

49. Zhang CC, Zhou JS, Hu JG, Wang X, Zhou XS, Sun BA, Shao C, Lin Q. Effects of IGF-1 on IL-1 $\beta$-induced apoptosis in rabbit nucleus pulposus cells in vitro. Mol Med Rep. 2013; 7:441-44. 
50. Liu Z, Zhou K, Fu W, Zhang H. Insulin-Like Growth Factor 1 Activates PI3k/Akt Signaling to Antagonize Lumbar Disc Degeneration. Cell Physiol Biochem. 2015; 37:225-32.

51. Zhang M, Zhou Q, Liang QQ, Li CG, Holz JD, Tang D, Sheu TJ, Li TF, Shi Q, Wang YJ. IGF-1 regulation of type II collagen and MMP-13 expression in rat endplate chondrocytes via distinct signaling pathways. Osteoarthritis Cartilage. 2009; 17:100-06.

52. Kim JS, Ellman MB, An HS, van Wijnen AJ, Borgia JA, Im HJ. Insulin-like growth factor 1 synergizes with bone morphogenetic protein 7-mediated anabolism in bovine intervertebral disc cells. Arthritis Rheum. 2010; 62:3706-15.

53. Lan PH, Liu ZH, Pei YJ, Wu ZG, Yu Y, Yang YF, Liu X, Che L, Ma CJ, Xie YK, Hu QJ, Wan ZY, Wang HQ. Landscape of RNAs in human lumbar disc degeneration. Oncotarget. 2016; 7:63166-76. doi: 10.18632/oncotarget.11334.

54. Ye D, Dai L, Yao Y, Qin S, Xie H, Wang W, Liang W. miR155 Inhibits Nucleus Pulposus Cells' Degeneration through Targeting ERK 1/2. Dis Markers. 2016; 2016:6984270.

55. Liu ZQ, Fu WQ, Zhao S, Zhao X. Regulation of insulin-like growth factor 1 receptor signaling by microRNA-4458 in the development of lumbar disc degeneration. Am J Transl Res. 2016; 8:2309-16.

56. Paul R, Haydon RC, Cheng H, Ishikawa A, Nenadovich N, Jiang W, Zhou L, Breyer B, Feng T, Gupta P, He TC, Phillips FM. Potential use of Sox 9 gene therapy for intervertebral degenerative disc disease. Spine. 2003; 28:755-63.

57. Sive JI, Baird P, Jeziorsk M, Watkins A, Hoyland JA, Freemont AJ. Expression of chondrocyte markers by cells of normal and degenerate intervertebral discs. Mol Pathol. 2002; 55:91-97.

58. Ren S, Liu Y, Ma J, Liu Y, Diao Z, Yang D, Zhang X, Xi Y, $\mathrm{Hu}$ Y. Treatment of rabbit intervertebral disc degeneration with co-transfection by adeno-associated virus-mediated SOX9 and osteogenic protein-1 double genes in vivo. Int J Mol Med. 2013; 32:1063-68.

59. Chang T, Xie J, Li H, Li D, Liu P, Hu Y. MicroRNA-30a promotes extracellular matrix degradation in articular cartilage via downregulation of Sox9. Cell Prolif. 2016; 49:207-18.

60. Tew SR, Pothacharoen P, Katopodi T, Hardingham TE. SOX9 transduction increases chondroitin sulfate synthesis in cultured human articular chondrocytes without altering glycosyltransferase and sulfotransferase transcription. Biochem J. 2008; 414:231-36.

61. Cheng CC, Uchiyama Y, Hiyama A, Gajghate S, Shapiro IM, Risbud MV. PI3K/AKT regulates aggrecan gene expression by modulating Sox 9 expression and activity in nucleus pulposus cells of the intervertebral disc. J Cell Physiol. 2009; 221:668-76.

62. Khan M, Maryam A, Qazi JI, Ma T. Targeting Apoptosis and Multiple Signaling Pathways with Icariside II in Cancer Cells. Int J Biol Sci. 2015; 11:1100-12.
63. Gruber HE, Hanley EN Jr. Analysis of aging and degeneration of the human intervertebral disc. Comparison of surgical specimens with normal controls. Spine. 1998; 23:751-57.

64. Ha KY, Koh IJ, Kirpalani PA, Kim YY, Cho YK, Khang GS, Han CW. The expression of hypoxia inducible factor-1alpha and apoptosis in herniated discs. Spine. 2006; 31:1309-13.

65. Ahsan R, Tajima N, Chosa E, Sugamata M, Sumida M, Hamada M. Biochemical and morphological changes in herniated human intervertebral disc. J Orthop Sci. 2001; 6:510-18.

66. Yang SD, Ma L, Yang DL, Ding WY. Combined effect of $17 \beta$-estradiol and resveratrol against apoptosis induced by interleukin- $1 \beta$ in rat nucleus pulposus cells via PI3K/Akt/ caspase-3 pathway. PeerJ. 2016; 4:e1640.

67. Sanford LP, Ormsby I, Gittenberger-de Groot AC, Sariola H, Friedman R, Boivin GP, Cardell EL, Doetschman T. TGFbeta2 knockout mice have multiple developmental defects that are non-overlapping with other TGFbeta knockout phenotypes. Development. 1997; 124:2659-70.

68. Baffi MO, Slattery E, Sohn P, Moses HL, Chytil A, Serra R. Conditional deletion of the TGF-beta type II receptor in Col2a expressing cells results in defects in the axial skeleton without alterations in chondrocyte differentiation or embryonic development of long bones. Dev Biol. 2004; 276:124-42.

69. Yang H, Wu J, Liu J, Ebraheim M, Castillo S, Liu X, Tang T, Ebraheim NA. Transplanted mesenchymal stem cells with pure fibrinous gelatin-transforming growth factorbeta1 decrease rabbit intervertebral disc degeneration. Spine J. 2010; 10:802-10.

70. Ni BB, Li B, Yang YH, Chen JW, Chen K, Jiang SD, Jiang LS. The effect of transforming growth factor $\beta 1$ on the crosstalk between autophagy and apoptosis in the annulus fibrosus cells under serum deprivation. Cytokine. 2014; 70:87-96.

71. Liu G, Cao P, Chen H, Yuan W, Wang J, Tang X. MiR-27a regulates apoptosis in nucleus pulposus cells by targeting PI3K. PLoS One. 2013; 8:e75251.

72. Imai S, Armstrong CM, Kaeberlein M, Guarente L. Transcriptional silencing and longevity protein Sir2 is an NAD-dependent histone deacetylase. Nature. 2000; 403:795-800.

73. Xia X, Guo J, Lu F, Jiang J. SIRT1 Plays a Protective Role in Intervertebral Disc Degeneration in a Puncture-induced Rodent Model. Spine. 2015; 40:E515-24.

74. Shen J, Fang J, Hao J, Zhong X, Wang D, Ren H, Hu Z. SIRT1 Inhibits the Catabolic Effect of IL-1 $\beta$ Through TLR2/SIRT1/NF-kB Pathway in Human Degenerative Nucleus Pulposus Cells. Pain Physician. 2016; 19:E215-26.

75. Zhou N, Lin X, Dong W, Huang W, Jiang W, Lin L, Qiu Q, Zhang X, Shen J, Song Z, Liang X, Hao J, Wang D, $\mathrm{Hu}$ Z. SIRT1 alleviates senescence of degenerative human intervertebral disc cartilage endo-plate cells via the p53/p21 pathway. Sci Rep. 2016; 6:22628. 
76. Wu JW, Wang JJ, Chen JB, Huang YL, Wang H, Liu GH, Li LF, Kang M, Wang XG, Cai HH. Resveratrol could reverse the expression of SIRT1 and MMP-1 in vitro. Genet Mol Res. 2015; 14:12386-93.

77. Gu X, Han D, Chen W, Zhang L, Lin Q, Gao J, Fanning S, Han B. SIRT1-mediated FoxOs pathways protect against apoptosis by promoting autophagy in osteoblast-like MC3T3-E1 cells exposed to sodium fluoride. Oncotarget. 2016; 7:65218-30. doi: 10.18632/oncotarget.11573.

78. Wang XL, Wu LY, Zhao L, Sun LN, Liu HY, Liu G, Guan GJ. SIRT1 activator ameliorates the renal tubular injury induced by hyperglycemia in vivo and in vitro via inhibiting apoptosis. Biomed Pharmacother. 2016; 83:41-50.

79. Yang B, Ma S, Wang YB, Xu B, Zhao H, He YY, Li CW, Zhang J, Cao YK, Feng QZ. Resveratrol exerts protective effects on anoxia/reoxygenation injury in cardiomyocytes via miR-34a/Sirt1 signaling pathway. Eur Rev Med Pharmacol Sci. 2016; 20:2734-41.

80. Liu B, Lei M, Hu T, Yu F, Xiao DM, Kang H. Inhibitory effects of SRT1720 on the apoptosis of rabbit chondrocytes by activating SIRT1 via p53/bax and NF-kappaB/PGC1alpha pathways. J Huazhong Univ Sci Technolog Med Sci. 2016; 36:350-355.

81. Jiang W, Zhang X, Hao J, Shen J, Fang J, Dong W, Wang D, Zhang X, Shui W, Luo Y, Lin L, Qiu Q, Liu B, Hu Z. SIRT1 protects against apoptosis by promoting autophagy in degenerative human disc nucleus pulposus cells. Sci Rep. 2014; 4:7456.

82. Miyazaki S, Kakutani K, Yurube T, Maeno K, Takada T, Zhang Z, Kurakawa T, Terashima Y, Ito M, Ueha T, Matsushita T, Kuroda R, Kurosaka M, Nishida K. Recombinant human SIRT1 protects against nutrient deprivation-induced mitochondrial apoptosis through autophagy induction in human intervertebral disc nucleus pulposus cells. Arthritis Res Ther. 2015; 17:253.

83. Wang D, Hu Z, Hao J, He B, Gan Q, Zhong X, Zhang X, Shen J, Fang J, Jiang W. SIRT1 inhibits apoptosis of degenerative human disc nucleus pulposus cells through activation of Akt pathway. Age (Dordr). 2013; 35:1741-53.

84. Wang B, Wang D, Yan T, Yuan H. MiR-138-5p promotes TNF- $\alpha$-induced apoptosis in human intervertebral disc degeneration by targeting SIRT1 through PTEN/PI3K/Akt signaling. Exp Cell Res. 2016; 345:199-205.

85. Zhao CQ, Wang LM, Jiang LS, Dai LY. The cell biology of intervertebral disc aging and degeneration. Ageing Res Rev. 2007; 6:247-61.

86. Pratsinis H, Constantinou V, Pavlakis K, Sapkas G, Kletsas D. Exogenous and autocrine growth factors stimulate human intervertebral disc cell proliferation via the ERK and Akt pathways. J Orthop Res. 2012; 30:958-964.

87. Pratsinis H, Kletsas D. PDGF, bFGF and IGF-I stimulate the proliferation of intervertebral disc cells in vitro via the activation of the ERK and Akt signaling pathways. Eur Spine J. 2007 2007; 16:1858-1866.
88. Mavrogonatou E, Kletsas D. Effect of varying osmotic conditions on the response of bovine nucleus pulposus cells to growth factors and the activation of the ERK and Akt pathways J Orthop Res. 2010; 28:1276-1282.

89. Hui W, Litherland GJ, Elias MS, Kitson GI, Cawston TE, Rowan AD, Young DA. Leptin produced by joint white adipose tissue induces cartilage degradation via upregulation and activation of matrix metalloproteinases. Ann Rheum Dis. 2012; 71:455-62.

90. Zhao CQ, Liu D, Li H, Jiang LS, Dai LY. Expression of leptin and its functional receptor on disc cells: contribution to cell proliferation. Spine. 2008; 33:E858-64.

91. Li Z, Shen J, Wu WK, Yu X, Liang J, Qiu G, Liu J. Leptin induces cyclin D1 expression and proliferation of human nucleus pulposus cells via JAK/STAT, PI3K/Akt and MEK/ ERK pathways. PLoS One. 2012; 7:e53176.

92. Li JJ, Chan WH, Leung WY, Wang Y, Xu CS. MicroRNA-21 promotes proliferation of rat hepatocyte BRL-3A by targeting FASLG. Genet Mol Res. 2015; 14:4150-60.

93. Liu Y, Wang X, Yang D, Xiao Z, Chen X. MicroRNA-21 affects proliferation and apoptosis by regulating expression of PTEN in human keloid fibroblasts. Plast Reconstr Surg. 2014; 134:561e-73e.

94. Xu J, Zhang W, Lv Q, Zhu D. Overexpression of miR21 promotes the proliferation and migration of cervical cancer cells via the inhibition of PTEN. Oncol Rep. 2015; 33:3108-16.

95. Liu H, Huang X, Liu X, Xiao S, Zhang Y, Xiang T, Shen $\mathrm{X}$, Wang $\mathrm{G}$, Sheng B. miR-21 promotes human nucleus pulposus cell proliferation through PTEN/AKT signaling. Int J Mol Sci. 2014; 15:4007-18.

96. Chen B, Huang SG, Ju L, Li M, Nie FF, Zhang Y, Zhang $\mathrm{YH}$, Chen X, Gao F. Effect of microRNA-21 on the proliferation of human degenerated nucleus pulposus by targeting programmed cell death 4. Braz J Med Biol Res. $2016 ; 49$.

97. Li W, Wang P, Zhang Z, Wang W, Liu Y, Qi Q. MiR-184 Regulates Proliferation in Nucleus Pulposus Cells by Targeting GAS1. World Neurosurg. 2017; 97:710-715.e1.

98. Wang J, Wang B, Chen LQ, Yang J, Gong ZQ, Zhao XL, Zhang CQ, Du KL. miR-10b promotes invasion by targeting KLF4 in osteosarcoma cells. Biomed Pharmacother. 2016; 84:947-953.

99. Chen H, Fan Y, Xu W, Chen J, Xu C, Wei X, Fang D, Feng Y. miR-10b Inhibits Apoptosis and Promotes Proliferation and Invasion of Endometrial Cancer Cells via Targeting HOXB3. Cancer Biother Radiopharm. 2016; 31:225-31.

100. Wang YY, Li L, Ye ZY, Zhao ZS, Yan ZL. MicroRNA-10b promotes migration and invasion through Hoxd10 in human gastric cancer. World J Surg Oncol. 2015; 13:259.

101. Yu X, Li Z, Shen J, Wu WK, Liang J, Weng X, Qiu G. MicroRNA-10b promotes nucleus pulposus cell proliferation through RhoC-Akt pathway by targeting 
HOXD10 in intervetebral disc degeneration. PLoS One. 2013; 8:e83080.

102. Ruocco N, Costantini S, Costantini M. Blue-Print Autophagy: Potential for Cancer Treatment. Mar Drugs. 2016; 14:14.

103. Cohen-Kaplan V, Livneh I, Avni N, Cohen-Rosenzweig C, Ciechanover A. The ubiquitin-proteasome system and autophagy: coordinated and independent activities. Int $\mathrm{J}$ Biochem Cell Biol. 2016; 79:403-18.

104. Zhang SJ, Yang W, Wang C, He WS, Deng HY, Yan YG, Zhang J, Xiang YX, Wang WJ. Autophagy: A double-edged sword in intervertebral disk degeneration. Clin Chim Acta. 2016; 457:27-35.

105. Kong CG, Park JB, Kim MS, Park EY. High glucose accelerates autophagy in adult rat intervertebral disc cells. Asian Spine J. 2014; 8:543-48.

106. Jiang L, Zhang X, Zheng X, Ru A, Ni X, Wu Y, Tian N, Huang Y, Xue E, Wang X, Xu H. Apoptosis, senescence, and autophagy in rat nucleus pulposus cells: I mplications for diabetic intervertebral disc degeneration. J Orthop Res. 2013; 31:692-702.

107. Ye W, Zhu W, Xu K, Liang A, Peng Y, Huang D, Li C. Increased macroautophagy in the pathological process of intervertebral disc degeneration in rats. Connect Tissue Res. 2013; 54:22-28.

108. Gruber HE, Hoelscher GL, Ingram JA, Bethea S, Hanley EN Jr. Autophagy in the Degenerating Human Intervertebral Disc: In vivo Molecular and Morphological Evidence, and Induction of Autophagy in Cultured Annulus Cells Exposed to Proinflammatory Cytokines-Implications for Disc Degeneration. Spine. 2015; 40:773-82.

109. Chen JW, Ni BB, Li B, Yang YH, Jiang SD, Jiang LS. The responses of autophagy and apoptosis to oxidative stress in nucleus pulposus cells: implications for disc degeneration. Cell Physiol Biochem. 2014; 34:1175-89.

110. Xu K, Chen W, Wang X, Peng Y, Liang A, Huang D, Li C, Ye W. Autophagy attenuates the catabolic effect during inflammatory conditions in nucleus pulposus cells, as sustained by NF- $\mathrm{BB}$ and JNK inhibition. Int J Mol Med. 2015; 36:661-68.

111. Heras-Sandoval D, Pérez-Rojas JM, Hernández-Damián J, Pedraza-Chaverri J. The role of PI3K/AKT/mTOR pathway in the modulation of autophagy and the clearance of protein aggregates in neurodegeneration. Cell Signal. 2014; 26:2694-701.

112. Zhang J, Zhang JX, Zhang QL. PI3K/AKT/mTORmediated autophagy in the development of autism spectrum disorder. Brain Res Bull. 2016; 125:152-58.

113. Liu ZQ, Zhao S, Fu WQ. Insulin-like growth factor 1 antagonizes lumbar disc degeneration through enhanced autophagy. Am J Transl Res. 2016; 8:4346-53.

114. Suzuki S, Fujita N, Hosogane N, Watanabe K, Ishii K, Toyama Y, Takubo K, Horiuchi K, Miyamoto T, Nakamura M, Matsumoto M. Excessive reactive oxygen species are therapeutic targets for intervertebral disc degeneration. Arthritis Res Ther. 2015; 17:316.

115. Dimozi A, Mavrogonatou E, Sklirou A, Kletsas D. Oxidative stress inhibits the proliferation, induces premature senescence and promotes a catabolic phenotype in human nucleus pulposus intervertebral disc cells. Eur Cell Mater. 2015; 30:89-102.

116. Chai J, Luo L, Hou F, Fan X, Yu J, Ma W, Tang W, Yang X, Zhu J, Kang W, Yan J, Liang H. Agmatine Reduces Lipopolysaccharide-Mediated Oxidant Response via Activating PI3K/Akt Pathway and Up-Regulating Nrf2 and HO-1 Expression in Macrophages. PLoS One. 2016; 11:e0163634.

117. Chu P, Han G, Ahsan A, Sun Z, Liu S, Zhang Z, Sun B, Song Y, Lin Y, Peng J, Tang Z. Phosphocreatine protects endothelial cells from Methylglyoxal induced oxidative stress and apoptosis via the regulation of PI3K/Akt/ eNOS and NF-kappaB pathway. Vascul Pharmacol. 2017; 91:26-35.

118. Krupkova O, Handa J, Hlavna M, Klasen J, Ospelt C, Ferguson SJ, Wuertz-Kozak K. The Natural Polyphenol Epigallocatechin Gallate Protects Intervertebral Disc Cells from Oxidative Stress. Oxid Med Cell Longev. 2016; 2016:7031397.

119. Alfieri A, Srivastava S, Siow RC, Modo M, Fraser PA, Mann GE. Targeting the Nrf2-Keap1 antioxidant defence pathway for neurovascular protection in stroke. J Physiol. $2011 ; 589: 4125-36$.

120. Demirel U, Yalniz M, Aygün C, Orhan C, Tuzcu M, Sahin K, Ozercan IH, Bahçecioğlu IH. Allopurinol ameliorates thioacetamide-induced acute liver failure by regulating cellular redox-sensitive transcription factors in rats. Inflammation. 2012; 35:1549-57.

121. Li W, Ma F, Zhang L, Huang Y, Li X, Zhang A, Hou C, Zhu Y, Zhu Y. S-Propargyl-cysteine Exerts a Novel Protective Effect on Methionine and Choline Deficient Diet-Induced Fatty Liver via Akt/Nrf2/HO-1 Pathway. Oxid Med Cell Longev. 2016; 2016:4690857.

122. Zhang G, Wang Q, Zhou Q, Wang R, Xu M, Wang H, Wang L, Wilcox CS, Liu R, Lai EY. Protective Effect of Tempol on Acute Kidney Injury Through PI3K/Akt/Nrf2 Signaling Pathway. Kidney Blood Press Res. 2016; 41:129-38.

123. Yang L, Rong Z, Zeng M, Cao Y, Gong X, Lin L, Chen Y, Cao W, Zhu L, Dong W. Pyrroloquinoline quinone protects nucleus pulposus cells from hydrogen peroxide-induced apoptosis by inhibiting the mitochondria-mediated pathway. Eur Spine J. 2015; 24:1702-10.

124. Cai XY, Xia Y, Yang SH, Liu XZ, Shao ZW, Liu YL, Yang W, Xiong LM. Ropivacaine- and bupivacaine-induced death of rabbit annulus fibrosus cells in vitro: involvement of the mitochondrial apoptotic pathway. Osteoarthritis Cartilage. 2015; 23:1763-75.

125. Xie RH, Yin M, Yin CC, Cheng XG, Xu ZW, Cao XQ, Chen WC. [Mechanism of chlorogenic acid on apoptosis 
of rat nucleus pulposus cells induced by oxidative stress]. Zhong Yao Cai. 2014; 37:465-69.

126. Bartels EM, Fairbank JC, Winlove CP, Urban JP. Oxygen and lactate concentrations measured in vivo in the intervertebral discs of patients with scoliosis and back pain. Spine. 1998; 23:1-7.

127. Risbud MV, Schipani E, Shapiro IM. Hypoxic regulation of nucleus pulposus cell survival: from niche to notch. Am J Pathol. 2010; 176:1577-83.

128. Ke Q, Costa M. Hypoxia-inducible factor-1 (HIF-1). Mol Pharmacol. 2006; 70:1469-80.

129. Risbud MV, Guttapalli A, Stokes DG, Hawkins D, Danielson KG, Schaer TP, Albert TJ, Shapiro IM. Nucleus pulposus cells express HIF-1 alpha under normoxic culture conditions: a metabolic adaptation to the intervertebral disc microenvironment. J Cell Biochem. 2006; 98:152-59.

130. Bach DH, Kim SH, Hong JY, Park HJ, Oh DC, Lee SK. Salternamide A suppresses hypoxia-induced accumulation of HIF- $1 \alpha$ and induces apoptosis in human colorectal cancer cells. Mar Drugs. 2015; 13:6962-76.

131. Paeng SH, Jung WK, Park WS, Lee DS, Kim GY, Choi YH, Seo SK, Jang WH, Choi JS, Lee YM, Park S, Choi IW. Caffeic acid phenethyl ester reduces the secretion of vascular endothelial growth factor through the inhibition of the ROS, PI3K and HIF-1 $\alpha$ signaling pathways in human retinal pigment epithelial cells under hypoxic conditions. Int J Mol Med. 2015; 35:1419-26.

132. Risbud MV, Fertala J, Vresilovic EJ, Albert TJ, Shapiro IM. Nucleus pulposus cells upregulate PI3K/Akt and MEK/ ERK signaling pathways under hypoxic conditions and resist apoptosis induced by serum withdrawal. Spine. 2005; 30:882-89.

133. Dai T, Zheng H, Fu GS. Hypoxia confers protection against apoptosis via the PI3K/Akt pathway in endothelial progenitor cells. Acta Pharmacol Sin. 2008; 29:1425-31.

134. Wang X, Li C, Liang A, Peng Y, Sun J, Huang D, Xu K, Ye $\mathrm{W}$. Regulation of a disintegrins and metalloproteinase with thrombospondin motifs 7 during inflammation in nucleus pulposus (NP) cells: role of AP-1, Sp1 and NF-kappaB signaling. Inflamm Res. 2016; 65:951-962.

135. Yuan FL, Zhao MD, Jiang DL, Jin C, Liu HF, Xu MH, $\mathrm{Hu} \mathrm{W}, \mathrm{Li} \mathrm{X}$. Involvement of acid-sensing ion channel 1a in matrix metabolism of endplate chondrocytes under extracellular acidic conditions through NF- $\mathrm{kB}$ transcriptional activity. Cell Stress Chaperones. 2016; 21:97-104.

136. Li P, Xu Y, Gan Y, Wang L, Ouyang B, Zhang C, Luo L, Zhao C, Zhou Q. Estrogen enhances matrix synthesis in nucleus pulposus cell through the Estrogen Receptor beta-p38 MAPK Pathway. Cell Physiol Biochem. 2016; 39:2216-2226.

137. Wang J, Chen H, Cao P, Wu X, Zang F, Shi L, Liang L, Yuan W. Inflammatory cytokines induce caveolin-1/ $\beta$-catenin signalling in rat nucleus pulposus cell apoptosis through the p38 MAPK pathway. Cell Prolif. 2016; 49:362-72.

138. Porta C, Paglino C, Mosca A. Targeting PI3K/Akt/mTOR Signaling in Cancer. Front Oncol. 2014; 4:64.

139. Yuan TL, Cantley LC. PI3K pathway alterations in cancer: variations on a theme. Oncogene. 2008; 27:5497-510. 